\title{
On the Semantic Correlation between Chinese Prepositional Case Frame and Predicate Case Frame
}

\author{
Jincheng Ju' ${ }^{1}$, Hua Zhang ${ }^{1}$, Qiuju Zhang ${ }^{2}$ \\ ${ }^{1}$ Forien Language College, Weifang University, Weifang, China \\ ${ }^{2}$ Construction engineering college, Weifang University, Weifang, China.
}

Keywords: Chinese Prepositional Case, Predicate Case.

\begin{abstract}
Based on the relationship and distinction between prepositional case frames and predicate case frames, this paper gets 26 monosyllable prepositions and 11 sorts of prepositional cases through use of CCL. The analysis shows that Chinese case frame is not parallel but stratificational. Predicate case frames are independent, while prepositional case frames are dependent, which are from predicate case frames and keep some features of predicate case frames. It is found that Chinese prepositional case frames and predicate case frames form a continuum, with prepositional case frames divided into typical and non-typical.
\end{abstract}

\section{Introduction}

The study of Chinese cases has been implied in 'Ma Shi Wen Tong', which is the first systematic grammar works in Chinese grammar history. With the continuous introduction of western linguistic theories and the development of Case Grammar, the studies of Chinese cases are also increasingly deepened and systemized both from research contents and from research methods. From research perspectives, there are mainly three tendencies in studies of Chinese cases: (1) valency of nominal elements based on classification of verbs; (2) valency of verbal elements based on classification of nouns; and (3) frame valency based on fusion of verbs and nouns.

This study aims to make a contrastive analysis of Chinese prepositional case frame from the perspective of construction grammar, and attempts to validate the following three points of view: (1) The case frame is the basis of cases and valencies, which rely on the frame, so the analysis of prepositional cases should take a frame as the presupposition, and they cannot be examined without the frame. (2) Chinese prepositional case frame is different from predicate case frame. The prepositional frame is dependent while the predicate frame is independent, so they should be used differently. (3) Chinese case frame is not parallel but stratificational. The prepositional case frame, which is highly grammaticalized, has vague meanings, so it is above predicate case frame. When the predicate case frame co-occurs with the prepositional case frame in the same language, the analysis should be made based on the predicate case frame, and the prepositional case frame should be integrated into the predicate case frame to determine their semantic relationship.

\section{From basic semantics to frame semantics}

Bolinger (1975:185) points out that 'Distinctive features make phonemes, phonemes make morphemes, morphemes words, words sentences, sentences discourses, discourses monologs or dialogues or stories or whatever, and these are puffed or puffable into novels, trilogies, encyclopedias, or higher units as large as one may please'. Based on Goldberg (1995:14), 'C is a CONSTRUCTION if $\mathrm{C}$ is a form-meaning pair $\angle \mathrm{Fi}, \mathrm{Si}>$ such that some aspect of $\mathrm{Fi}$ or some aspect $\mathrm{Si}$ is not strictly predictable from C's component parts or from other previously established constructions'.

In other words, the semantic composition is not made by unordered random combination of lower semantic units, but an overall expression of the frame meanings of lower semantic units, and meanings should be stratificational and frame dependent. 


\section{Distinction between prepositional case frame and predicate case frame}

Firstly, the preposition and the verb are two different word classes. Zhang Bin (2010) points out that most of prepositions in modern Chinese come from verbs in old Chinese by grammaticalization. The imbalance of linguistic development and the gradualness and complexity of grammaticalization make prepositions and verbs overlap and some of verbs are in the course of transformation to prepositions. In addition, he distinguishes verbs from prepositions and points out four differences between them; namely, prepositions cannot be used as predicate, cannot take complements, cannot be repeated and cannot take tense auxiliaries. Secondly, a prepositional case frame is different from that of a predicate from the perspective of Frame Semantics. Compared with a predicate case frame, a prepositional case frame has different degree of word order transformation and different position in the whole semantic expression. From the perspective of degree of word order transformation, a predicate case frame is relatively free. The predicate in a frame can be moved, substituted and even deleted in a sentence, but the preposition in a frame cannot be moved, substituted or deleted. For example:

（1）a.小王骑走了车子。/车子，小王骑走了。/小王偷走了车子。/车子! （小王骑走了） b. 火车出发了。/出发了, 火车。/ 火车动了。/火车! (出发了)

c. 别拿我东西。/我东西, 别拿。/别动我东西。/我东西! (别拿)

(2) a. 小王把车子骑走了。/*把车子, 小王骑走了。/*小王把[]骑走了。

b. 火车从上海站出发了。/*从上海站, 火车出发了。/*火车从[ ]出发了。

c. 别拿我出气。 $/ *$ 拿我, 别出气。 $/ *$ 别拿 [] 出气。

(1) is the transformation of predicate cases in three predicate case frames. The movement, substitution or deletion can be made without making the sentence ungrammatical. However, the movement or deletion in (2) cannot be allowed in Chinese grammar. From the position of frame meanings in whole semantic expression, a predicate case frame is in the central position and has independent expression function, while a prepositional case frame is in the peripheral position and needs to be dependent upon other predicate cases frame to show its semantic function.

（3）a.敌人很快又冲了上来。

b. 离了你, 什么都不行。

c. 在这方面不能比。

（4）a.他近来老是冲我发火。

b.离北京还有五公里。

c. 小王比我强多了。

(3) is a predicate case frame, so the sentence can independently express clear meanings without relying on any other frames. Even if there are other predicates in a sentence, the sentence is not a simple but a complex sentence. (4) is a prepositional case frame. The meanings of the sentence cannot be expressed only by the prepositions, which are only complements to the predicate case frames, so a sentence is still simple even if it has both a preposition and a predicate.

\section{Predicate-prepositional case frame hierarchy}

The dependency of a prepositional case frame can be examined from the semantic function and ellipsis of a prespostion. Zhang Bin (2010: 221-222) examines the ellipsis of prepositions from semantics, collocation, syntactic position and syllable. He points out that from the perspective of semantics, the prepositions whose meanings are relatively more bleached and used more frequently may be deleted, while those with more lexical content and lower frequency of use cannot be deleted. As for the meanings expressed by prepositions, those that is related to dative, comparison and disposal are rarely deleted, while those that is concerned with aboutness, time and location are often deleted. As for collocation, if a preposition is followed by an arbitrary reference pronoun or a locative, it can be deleted; if a preposition 
follows other adverbs or volitive auxiliaries, it must be used. Viewed from syntactic position, the prepositional phrases in front of subjects often delete prepositions of aboutness, time and locative; those in front of verbs often delete prepositions of instrument and reliance; the following verbs often delete prepositions of locative and objective. The frequency of deletion is ranked as in front of subjects>after verbs >in front of verbs. Based on the above mentioned, the relationship between syntactic position and preposition deletion is listed as Table 1.

Table 1: Relationship between Syntactic Position and Prepositional Deletion

\begin{tabular}{|c|c|c|}
\hline $\begin{array}{l}\text { Syntactic Position } \\
\text { (order) }\end{array}$ & Deletable Prepostions & Undeletable Prepositions \\
\hline In front of Subject & Tine, locative and aboutness & \\
\hline After Verbs & Locative, objective & \\
\hline In front of Verbs & Instrument, reliance & $\begin{array}{c}\text { Disposal, comparison, } \\
\text { dative }\end{array}$ \\
\hline
\end{tabular}

Although the table above does not list all prepositional cases and make explanations about the prepositional deletion, it is enough to lay a solid foundation for justification of dependency of prepositional case frames, so how many cases should a prepositional case frame have? We can make analysis based on prepositional classifications and their semantic functions. Zhang Bin (2010: 215) classifies monosyllable prepositions into typical prepositions, ordinary prepositions and special prepositions, which are 27 in total, and classifies disyllable prepositions into derivative prepositions and compound prepositions, which are 34 in total. Based on the functions of prepositional phrases, they are divided into adverbial, attributive, complementary and sentence-initial modifiers. According to the classifications of monosyllable prepositions, we use CCL (corpus built by Beijing University) to verify and get 26 monosyllable prepositions and 11 sorts of prepositional cases.

Table 2: Correspondence between Prepositional Cases and Prepositions

\begin{tabular}{|c|c|}
\hline Prepositional Cases & Prepositions \\
\hline Time & 当 \\
\hline Locative & 在、于 \\
\hline Starting Point & 自、从、打 \\
\hline Finishing Point & 到、至 \\
\hline Direction & 朝、向、往、沿 \\
\hline Manner & 以、用 \\
\hline Reliance & 据、照、随 \\
\hline Aboutness & 就、对 \\
\hline Disposal & 把、将、管、拿、冲 \\
\hline Comparison & 比 \\
\hline Dative & 和、跟 \\
\hline
\end{tabular}

It should be pointed out that although the range of typical prepositions is clear cut, the classifications made above cannot be exhausted because there exist some transitional prepositions and non-typical prepositions. According to markedness theory and categorization theory, the typical prepositions are unmarked, and the rest are marked, so can the deletion of prepositions embody the typicality of prepositional cases? The answer is affirmative. In line with Zhang Bin (2010: 221-222), we can summarize the dependency hierarchy of prepositional case frames as follows: 
Table 3: Dependency Hierarchy of Prepositional Case Frames

Syntactic Position (order)
In front of Subject(deleted)
After Verbs(deleted)
In front of Verbs(deleted)
In front of Verbs(not deleted)

Syntactic Position (order)

After Verbs(deleted)

In front of Verbs(not deleted)

According to categorization theory, the more typical a category is, the more prototypical it is. In other words, the core members of a category rely less on other categories because of their strong typicality. It is the same case with prepositional case frames and predicate case frames. Table 3 highlights the vagueness and gradualness of the cases in prepositional case frames. The most typical in prepositional case frames should be "time, locative and aboutness"; next should be "starting point, finishing point and direction"; and the following should be "manner and reliance. The non-typical in prepositional case frames should be "disposal, comparison and dative". The most typical word order of prepositional case frames in a sentence is in the front of subjects; next is after verbs and the final is in front of verbs. It is shown from the fact that "disposal, comparison and dative" before verbs are rarely deleted that the relationship between prepositional case frames and predicate case frames can be revealed. The "disposal" in prepositional case frames generally falls on "patient", while "comparison" and "dative" often fall on "agent" in predicate case frames. Sometimes it is hard to distinguish the two because prepositional case frames are originally from predicate case frames. Just because prepositional case frames are used separately more frequently, it seems that they have already got rid of control and influence of predicate case frames, but we could still find out the dependency of prepositional case frames on predicate case frames.

\section{Conclusion}

Based on the relationship and distinction between prepositional case frames and predicate case frames, this paper gets 26 monosyllable prepositions and 11 sorts of prepositional cases through use of CCL. The analysis shows that Chinese case frame is not parallel but stratificational. Predicate case frames are independent, while prepositional case frames are dependent, which are from predicate case frames and keep some features of predicate case frames. It is found that Chinese prepositional case frames and predicate case frames form a continuum, with prepositional case frames divided into typical and nontypical.

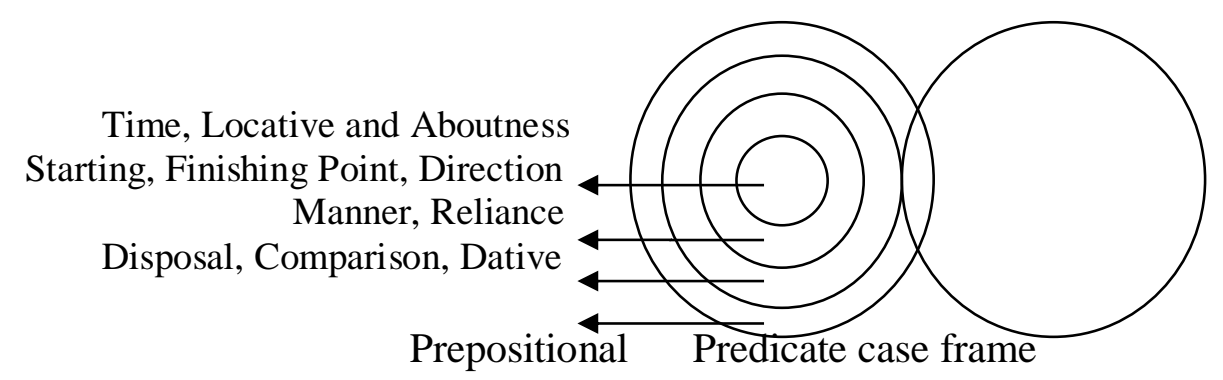

The most typical in prepositional case frames should be "time, locative and aboutness"; next should be "starting point, finishing point and direction"; and the following should be "manner and reliance. The non-typical in prepositional case frames should be "disposal, comparison and dative". The most typical word order of prepositional case frames in a sentence is in the front of subjects; next is after verbs and the final is in front of verbs.

\section{References}

[1] Comrie, Bernard. 2010. "Language Universals and Linguistic Typology", Beijing University Publishing House.

[2] Fillmore, C.J. 2012. "The Case for Case", Commercial Press. 
[3] Lindsay, J. and Whaley. 1997. "Introduction to Typology, the Unity and Diversity of Language", Sage Publications.

[4] Liu Zhengguang. 2011. "Research on Construction Grammar", Shanghai Foreign Language Education Press.

[5] Lu Jianming. 2004. "Multi-functionality of Syntax and Semantics", Foreign Languages.

[6] Shen Jiaxuan. 2009. "Cognition and Studies of Chinese Grammar", Commercial Press.

[7] Yuan Yulin. 2005. "Research on Valencies of Chinese Verbs", Jiangxi Education Press. 